\title{
MARÍA ZAMBRANO Y EL SENTIDO RELIGIOSO DE LA EXISTENCIA:
}

\author{
MARÍA ZAMBRANO AND THE RELIGIOUS \\ SENSE OF EXISTENCE
}

\section{RODRIGO PULGAR CASTRO***}

\section{RESUMEN}

Este trabajo se propone mostrar los efectos de la religiosidad en la determinación del sentido de la existencia. Por tal razón, partimos del presupuesto de que la pregunta fundamental que anima la investigación filosófica de Zambrano se elabora en un proceso cuyo eje es la intersubjetividad y la trascendencia que concluye en la idea de persona; idea que, a su vez, es una señal sobre el significado de la palabra como expresión efectiva del diálogo Dios-hombre.

Palabras clave: Filosofía, Dios, persona, intersubjetividad, razón poética.

\section{ABSTRACT}

This work proposes to show the effects of religiousness in the determination of the sense of existence. For such a reason, we depart from the presupposition that the fundamental question that motivates Zambrano's philosophical investigation is elaborated in a process whose axis is intersubjectivity and transcendence, and that concludes in the idea of person; an idea that in turn, is a sign of the meaning of the word as an effective expression of the dialogue between God-man.

Keywords: Philosophy, God, person, intersubjectivity, poetic reason.

Recibido: 30.05.14. Aceptado: 20.01.15.

\footnotetext{
* Trabajo realizado en el marco del proyecto FONDECYT Regular N ${ }^{\circ} 1110224$.

** Profesor del Departamento de Filosofía, Facultad de Humanidades y Arte, Universidad de Concepción. Concepción, Chile. Correo: rpulgar@udec.cl
} 


\section{INTRODUCCIÓN}

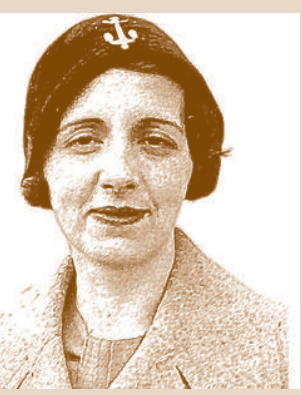

M. Zambrano
$\mathrm{P}$ REVIO A CUALQUIER MENCIÓN respecto de aquellos elementos que María Zambrano señala a propósito del sentido religioso de la existencia, es bueno recordar que cuando Dios es la interrogante que ocupa el hacer filosófico, nos topamos con discursos o argumentos variados que intentan responder sobre su existencia y sentido (Cfr. Izquierdo, 2003). Pero cuando se va más allá de la textura argumentativa de cada discurso, se pueden identificar tanto los elementos que componen o dan vida a los postulados ahí recogidos como a los aspectos teóricos e interpretativos que hacen de cada discurso un relato original explicativo del vínculo entre Dios y el hombre. Ahora, cuando se entra en posesión de los elementos que componen los discursos, entonces significa que se está en condiciones de decir lo que efectivamente se comprende y, por tanto, también en condiciones de ingresar en la dinámica de poder identificar qué de aquello es posible de traducir para su comunicación efectiva. Así, y según lo que se entiende de los diversos argumentos filosóficos sobre Dios, se aceptan en general dos criterios: a) la riqueza argumentativa que se consigue tener a razón de los efectos comprensivos de aquello que traduce la plural experiencia humano de Dios, y b) el número de relatos que intentan mostrar por consecuencia la inteligencia humana de lo sacro. Ambos criterios hacen posible la filosofía de la religión. A esta tesis se suma lo que Paul Ricoeur indica respecto del significado del discurso sobre lo religioso; especialmente, lo que describe a raíz de su análisis y postulado del segundo presupuesto que caracteriza el lenguaje propiamente religioso:

La segunda presuposición es que el discurso religioso no carece de sentido. Dicho de otra manera, vale la pena examinarlo pues algo se dice en él que no se dice en otras modalidades del discurso: discurso ordinario, discurso científico, discurso poético. En términos positivos: el lenguaje religioso es sensato, posee un sentido, al menos para la comunidad de fe, cuando lo usa para comprenderse a sí misma o para hacerse comprender por un auditorio extraño (Ricoeur, 2008, p. 51).

En esta misma línea, tampoco se puede soslayar la sentencia de Richard Schaeffler:

Así pues, mientras el concepto filosófico de esencia, que responde a la pregunta 'qué es Dios', queda fijado mediante una definición, el nombre de Dios, por el que preguntan los hombres religiosos, se utiliza más bien en los relatos. La existencia o no de Dios, debatidas en la teología filosófi- 
ca, han de demostrarse con argumentos; las teofanías, en cambio, no son el resultado de una concatenación de argumentos, sino contenidos de experiencias vividas. Sin embargo, al constatar que tanto en las religiones como en la teología filosófica se pregunta por Dios de modo tan distinto y se habla de él de forma tan diversa, entonces surgen dudas sobre si, al final, ambas se refieren a lo mismo cuando emplean el vocablo 'Dios'. Pues el 'Dios de los filósofos' parece ser distinto del Dios al que se reza en las religiones y cuyas hazañas se proclaman en ellas (Schaeffler, 2003, p. 46).

Apoyados en la sentencia tanto de Ricoeur como de Schaeffler (2003), es plausible afirmar que los argumentos sobre Dios son elaboraciones teóricas que poseen valor de contexto, esto a causa de que los discursos provienen de descubrimientos de sentidos que relacionan a Dios con personas, momentos y lugares determinados. Pues bien, de este juego intelectivo-discursivo Zambrano no escapa, al contrario, es conciente de la necesidad de enfrentarlo, puesto que su interés filosófico se ordena a buscar los diversos significantes que adquiere la relación Dios-hombre. Esto explica por qué Zambrano no evita la pregunta filosófica sobre las significaciones posibles, sino que se atreve a dar curso a una propuesta de reflexión cuyo objetivo es acceder precisamente al significado de la experiencia de Dios para quien la sufre; hasta dar con una intención filosófica cuyo efecto es una reflexión sobre Dios permeada por lo cultural. Es precisamente al alero de este factor interpretativo que su filosofía de la religión se vuelve un discurso fenomenológico sobre Dios, puesto que recoge para su desarrollo las distintas experiencias que los hombres -a lo largo del tiempo- han tenido sobre lo sacro. Esta perspectiva se transparenta en su texto El hombre y lo divino; lugar en donde afirma que "La realidad es lo sagrado y sólo lo sagrado la tiene y la otorga" (Zambrano, 1993, p. 33).

La afirmación de la malagueña se inserta en la hipótesis de que la identidad de una cultura se funda en el contexto y desarrollo de un tipo de relación particular que se da entre dos polos: Dios y el hombre. Al respecto, no es menor que sea ahí en este continente relacional, donde se declare la identidad de una cultura; identidad fundada en el contexto y desarrollo de un tipo de relación particular gestionada, tanto en su origen como en su consolidación, por una acción del tipo sincrónico dada entre estos dos polos. Esta idea de relación en lenguaje de Zambrano se traduce como una afirmación respecto a que la cultura, su génesis y desarrollo depende de la comprensión que de Dios (dioses en culturas politeístas) tengan los hombres, pero también de la calidad de estos dioses respecto del sujeto y sus demandas de respuestas (Cfr. Zambrano, 1993, p. 27). 
El significante de este juego descriptivo es la sustancia que califica la filosofía de Zambrano como una filosofía original. En efecto, la evidencia de la investigación filosófica sobre el vivir práctico religioso demuestra $-y$ en ello la obra total de Zambrano responde a esta demanda- que la realidad de los seres adquiere su total y completa plenitud sobre la base de la onticidad de las entidades divinas, es decir, su reflejo en lo histórico. Por ello no es menor que Zambrano cite de Scheler y desde El puesto del hombre en el cosmos, la idea que describe al hombre "como la de alguien que no tiene un espacio propio, un medio, una casa" (Zambrano, 1993, p. 33). Tampoco es arbitrario que insista en el hecho de que: "La aparición de un dios representa el final de un largo período de oscuridad y padecimientos. Y es el suceso más tranquilizador de todos los que puedan ocurrir en una cultura; señal de que el pacto, la alianza, está concluido" (Zambrano, 1993, p. 34).

Pero, ¿por qué insistir en la tesis de la religiosidad como el aspecto central del pensamiento filosófico de María Zambrano? Pues simplemente por entender que en los estudios filosóficos de la malagueña hay una constante: la presencia de un movimiento entre Dios y el hombre capaz de dar vida a una realidad con características singulares. Para esto es preciso que la relación en su onticidad reconozca que cada componente, vale decir, cada polo o cada extremo de la relación que da sentido y existencia a la relación misma, defina su acción desde el otro, no desde simplemente sí-mismo; lo cual implica aceptar que el actuar de uno respecto del otro es propio de un suceso dinámico que valida cada polo y, por efecto, la relación misma. Mas este vínculo que expresa vitalmente un asunto de realidad intersubjetiva, simplemente nos pone de cara con la arquitectura religiosa al tener ésta su origen en el continente de una realidad supra-personal; realidad por medio de la cual la existencia humana atravesada por la piedad (Cfr. Pérez Borbujo, 2010) entrega el significado al conjunto de la realidad y al curso de la historia (Cfr. Martín Velasco, 1995). No olvidamos aquí que la piedad es el subyecto de la relación entre Dios y el hombre, y por medio de la cual se adquiere el significante último de realidad humanizada, que lo es por responder también como realidad supra-personal. Todo este proceso tiene necesaria consecuencia en la elaboración de diversos significados humanos y cuyo resultado es la comunidad humana.

\section{ALGUNAS CLAVES DE INTERPRETACIÓN}

Un recorrido por la historia de Zambrano es la mejor prueba que el tema de lo religioso ocupa su tiempo y sus preocupaciones más fundamentales. 
Se da así el caso que, por ejemplo, el tema de la razón poética, considerado su gran aporte a la historia de la filosofía al menos hispánica (idea de la cual participan sin variación los estudiosos de la obra de Zambrano) ${ }^{1}$, resulta ser tributario a la filosofía de la religión. Síntoma que su aporte no es un asunto separable de la matriz filosófica principal que consiste en una reflexión sobre la sacralidad. Además que Zambrano, en sentido estricto, se apropia de un presupuesto heurístico que permita conocer: a) cuánto de lo religioso afecta al sujeto, b) qué significa la experiencia tiempo-espacial de lo religioso para el sujeto. Con este presupuesto de investigación, Zambrano puede avanzar en dilucidar el lugar de Dios en la historia humana.

Es cierto que una lectura hermenéutica al carácter singular del examen fenomenológico a la cuestión religiosa devela que la pregunta filosófica sobre su sentido es, en el caso de Zambrano, una situación abierta, pues existe una óptica epistémica que reconoce valor al proceso de buscar una adecuada comprensión del hecho religioso, pues asume que si lo que en verdad importa es entender los extremos de la relación y sus efectos en uno de los polos, en este caso: el hombre; quien necesariamente aparece como la clave hermenéutica para el buscar; buscar comprendido como proceso y también como continente de investigación. Una prueba del valor epistémico de la búsqueda lo constituye su estudio sobre Séneca, pues la filósofa cree ver en él la posibilidad de una real heurística sobre el significado del proceso de develamiento del sentido religioso español.

\subsection{La herencia de un modo de existir}

Según Zambrano, Séneca "se nos aparece desde esa lejanía extrahumana ya. Al revés, le sentimos por encima de nosotros, pero cercano, familiar..." (Zambrano, 2011b, p. 15), es decir, siendo parte de una unidad de sentido (y en cierto sentido responsable de aquello); sentido del cual se siente heredera, pues cuando Zambrano se ocupa de la pregunta por el sentido, descubre una forma de ser sostenida en la tradición y cultura hispánicas. Mas para lograr plena comprensión de sentido (no se debe olvidar que es su propia comprensión la que está en juego), postula lo imprescindible de la comunidad humana; especialmente si aquélla es percibida como ese lugar específico en donde prima la presencia de una realidad supra-personal. Reunida esta condición, entonces si se trasunta la herencia por correspon-

\footnotetext{
${ }^{1}$ Es una idea de la cual participan Maillard, Bungard, Ortega Muñoz, Jesús Moreno, entre tantos otros estudiosos del pensamiento de María Zambrano..., idea que también comparto.
} 
dencia que -diremos con Marcel- "sólo puede encontrarse donde existe una unidad orgánica y concreta, no una simple acumulación de números. Sólo en ese caso se puede hablar de herencia" (Marcel, 1967, p. 66).

La hipótesis de la existencia de una variable que permita hablar de comunidad humana, e identificable en su peculiaridad $u$ originalidad de sentido para alguien en particular, gracias a ser la variable heredable, es sacada a la luz por medio de una hermenéutica cuyo objetivo es resolver la conexión entre la tradición y un sujeto. En este sentido, Zambrano se convierte en aquel ejemplo de una vida particular cuyo sostén de legitimidad es la comunidad humana. Ahora bien, la hipótesis de lo heredable en sí se legitima en una existencia caracterizable como manifestación de un existir vital, es decir, de un existir que se explica desde aquel entender que se existe como manifestación de una herencia de sentido que se comparte con, entre otros afirmaría Zambrano, Séneca.

Comprendido el sentido existencial heredado, entonces sí el sentir con Séneca es un sentir amplificante, pues se da dentro de un todo unitariodinámico de sentido; sentir que, a su vez, corresponde a aquella mirada interpretativa que concluye en afirmar que Séneca es "uno de los sabios que realizaron mejor ante los ojos de la gente ese retorno a la antigua fe" (Zambrano, 2011b, p. 26), vale decir, uno de aquellos hombres que mejor refleja en su existencia el proceso humanizante; proceso que en el caso de la interpretación de María Zambrano corresponde al significado de lo hispánico; tejido referencial cuya puntada inicial está en tiempos de Séneca pasando por la poesía mística de San Juan de la Cruz; poeta místico que resulta para Zambrano representación paradigmática de un tiempo axial; tiempo de la mística que favorece el desarrollo de un talante de comprensión y significación religiosa desde la paradoja que implica la ausencia del amado:

El motivo ausencia en el amor, es un motivo claramente platónico que a los historiadores de la literatura les compete estudiar. "Ausencia" en el amor, porque la presencia jamás es posible y si alguna vez se diera, ya no se cantaría.

Así, El Cántico Espiritual del místico San Juan de la Cruz, es el canto a la ausencia del amado. Aquí explicable porque su amado, en efecto, no es visible. Pero, en la poesía profana de este tiempo y del anterior se vería también constantemente este motivo de ausencia y de búsqueda constante de las huellas del amado (Zambrano, 2001a, p. 69).

La referencia a San Juan de le Cruz introduce -en clave hermenéuticala presencia de lo absoluto vistiendo de explicación metafísica-religiosa el ser de la existencia. Pero esta explicación no queda reducida a la existen- 
cia humana, sino que alcanza la realidad física toda. Esta interpretación la vamos a reforzar con Bungard, quien se detiene en la significación de San Juan de la Cruz en la determinación del postulado de la razón poética como vía de acceso comprensivo al sentido de lo absoluto para la existencia:

Bajo la presencia de san Juan de la Cruz, construye la autora desde la época mexicana una razón poética que vuelve siempre a los orígenes, al sentir originario del ser. De esta forma, oscilando dialécticamente entre el no ser y el ser, la razón traspasa los límites del entendimiento e intuye en un 'claro' de la conciencia la presencia de lo absoluto (Bungard, 2005, p. 131).

\subsection{La vía poética}

En propiedad de un criterio metafísico-religioso que actúa como substrato poiético-comprensivo de la existencia, y en donde la poesía de San Juan de la Cruz es central, Zambrano entrega a la filosofía una vía epistemológica que pone a la tarea de dar cuenta de la situación religiosa. Creo entender que la razón poética es, por sobre toda otra cuestión, una forma de la razón que guarda la característica de la poesía con un fin comprensivo respecto de la verdad religiosa asociada al sentido de lo humano. Con ello, el substrato epistémico de la poesía, es fiel a la cuestión del preguntar genuinamente filosófico, puesto que como pregunta -declara la filósofa- es una que "dirigida a la divinidad -revelada o develada poéticamente- ha sido la angustiada pregunta sobre la propia vida humana" (Zambrano, 1993, p. 35), y cuyo carácter se define al tiempo que el preguntar es uno enganchado a la tradición religiosa más original; situación que en definitiva resuelve interrogativamente el estado de los hombres y de las cosas:

La aparición de dioses como Apolo, y la revelación de Jehová, señalan así la aparición de lo más humano del hombre: el preguntar, el hacerse cuestión de las cosas. Mas, no son ciertamente las cosas inanimadas las que sugieren la pregunta. A lo que sabemos, nunca se han preguntado ante ningún dios cuestiones de conocimiento (Zambrano, 1993, p. 35).

El hecho interrogativo existencial sobre lo religioso se descubre en la dinámica que constituye la vida. Este fenómeno es comprendido a partir del ejemplo de un hombre que sufre la mudanza que implica $e l$ vivir instalado en el intentar desarrollar una respuesta de sentido. La consecuencia de este vivir la mudanza convierte en significativo el buscar mismo para el aparecer de la conciencia. En efecto, "la actitud de preguntar supone la aparición de la conciencia; de la conciencia, ese desgajamiento del alma (...), este 


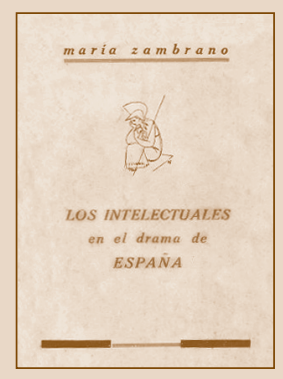

desgajamiento del alma, la pérdida de la inocencia en que surge la actitud consciente no es sino la formulación, la concreción de una larga angustia" (Zambrano, 1993, p. 35). Desgajamiento cuyo efecto es la aprehensión de las notas de humanidad a raíz de la apertura a otra realidad, una suprapersonal que entrega los elementos comprensivos que dan sentido a la humanidad misma. Mas ciertamente la acción humana desde sus orígenes se desarrolla en varios tipos, uno de éstos es poesía, y que ocupa un lugar de privilegio en el proceso de comprensión de la verdad. Este lugar nace a raíz del vínculo que la poesía tiene con el hombre y su historia:

Como todo lo humano, la poesía une vida y existencia, a menudo la una a costa de la otra y rara vez unidas en venturosa unidad. Y entonces, cuando esto se realiza, algo es verdaderamente (...), la poesía está entrelazada con la historia, subyugada por ella, amenazada siempre hasta cuando contra ella se revela para rescatarse (...) Se diría que sometida a la ley de esta cruz entre vida y existencia ha de estarse rescatando en ella continuamente, teniendo que respirar sin darse respiro (Zambrano, 1991, p. 50).

Pero ¿qué es la razón poética? De partida, este concepto refiere a un proceso que se inaugura el año 1937 al comentar Zambrano el texto de Antonio Machado La guerra. El comentario de la filósofa asume como clave el contexto de compromiso político del poeta; esto le permite identificar -junto con mencionar directamente razón poética- la tarea del poeta: "Los hondos laberintos de esta razón poética, de esta razón reintegradora de la rica substancia del mundo. Baste reconocerla como médula de la poesía de Antonio Machado" (Zambrano 1986, pp. 68-69).

Pero, ¿qué le aporta a Zambrano la razón poética? Y asociado a esto ¿cuál es su novedad? Lo primero, una evolución de la razón filosófica misma, puesto que se abre a reconocer que la verdad es posible de conocer de modo poético en tanto lo poético la revela. Lo segundo, tiene que ver con aquella novedad respecto que la razón poética se constituye como razón transformadora del sujeto mismo, por lo tanto, la tesis es que no sólo consiste en ser una razón que se ocupa de los objetos olvidados o desechados por la vieja razón, que es un aspecto que Zambrano reflexiona apoyada en su maestro Ortega y Gasset; particularmente sobre el efecto que tiene la razón moderna en la vida humana: "La vida instalada en el lugar del conocimiento resulta al propio tiempo sometida a él y deificada. El primer aspecto fue denunciado por Ortega y Gasset en su crítica al idealismo desde su 'Tesis metafísica acerca de la razón vital”' (Zambrano, 1993, p. 21). 
Lo cierto que en su afán de discutir el rol de la filosofía para un hacerse efectivo de la verdad religiosa, así como de sus notas determinantes de significación para el hombre, la filósofa acaba por distanciarse de la forma moderna de la razón, optando por una razón que se desliza por sus interiores con el objetivo de recuperar el sentido de lo humano que, en su caso, deriva del sentido de lo religioso. Para cumplir tal tarea, Zambrano construye una filosofía que hace de la poesía un instrumento epistemológico capaz de aclarar las notas que derivan de la experiencia humana de lo divino. Con este instrumento se enfoca a dilucidar el continente de esencias derivadas de la experiencia religiosa ${ }^{2}$, y que son descubiertas en una geografía intersubjetiva; continente de sentido que devela el ser oculto de la existencia misma. Pero, ¿por qué tanto interés de hacer este ejercicio de intelección sobre la experiencia religiosa? La respuesta es que Zambrano cree que la gran tragedia humana es "no poder vivir sin dioses" (Zambrano, 1993, p. 14); de ahí la explicación hallada en el centro motriz de su filosofía sobre que el hombre lo es "en alteridad en relación con lo otro, con lo demás, porque todo sí mismo supone y exige otro frente a lo que serse y definirse" (Ortega Muñoz, 1994, p. 125); en donde el otro es en rigor Dios. Asunto que deriva en decir que se es persona en tanto existencia abierta a la presencia de un ser esencial que acaba por definirlo como sujeto peculiar dispuesto a reconocerse en aquel otro.

\section{EL AMOR Y LA TRASCENDENCIA}

El sostener la hipótesis de que la propuesta filosófica defendida por Zambrano es onto-teológica y que Bungard da por sellado: "A partir de 1955, el pensamiento de Zambrano gira en torno a la idea de lo absoluto, de lo inefable e inasible de la realidad y adquiere el carácter de onto-teología" (Bungard, 2005, p. 387), no significa que la propuesta consista en un postulado construido en respuesta al paradigma moderno de:

creer que la realidad toda, vida humana inclusive, está compuesta de hechos sometidos a causa a las que se llaman razones, volviendo así al sentido inicial de la 'ratio' latina: cuentas. Para este hombre, positivista a veces sin saberlo, buscar y dar razones es echar cuentas (Zambrano, 1998, p. 26).

\footnotetext{
${ }^{2}$ Cfr. Bungard (2000, p. 387), op. cit., dice: "se trataría de una hermenéutica de esencias. La ontología por ella propuesta es resultado de un 'descifrar' el sentir sobre el ser oculto”.
} 
Ahora es verdad que su filosofía es calificable de paradojal por ser ontoteológica desde el momento que acepta como verdadero que:

los movimientos más recónditos y esenciales del ser humano -del humano al menos- si consumen tiempo y proponen un espacio cualitativo cuando de movimientos del ser se trata, se dan en función de la luz, una luz que le llega y que le despierta y que tiene que ser a su vez anhelada, una luz de la que tiene que ir al encuentro (Zambrano, 2011a, p. 140).

\subsection{El amor y la imagen}

Con esta idea de base, es viable sostener que uno de los valores filosóficos de la obra de Zambrano es la vía poética para lograr comprender las estructuras comunicativas de lo que se cree, como son la creación y cristalización de formas que responden al querer mostrar toda esa realidad que trasciende

Filosofia

y poesía

Maria Zambrano

船 la razón misma. Esta formas son, en general, modos sostenidos en un creer identificado con el amor y cuya "forma adecuada, su envoltura es una imagen; la imagen primera que el hombre es capaz de formarse, esto es: una imagen sagrada, que reaparecerá siempre en el delirio del amor" (Zambrano, 1993, p. 30).

Es un síntoma, particularmente en la reflexión sobre la complejidad de las formas que dicen lo que es Dios, que el descubrimiento del amor corra paralelo y en un tiempo al de la filosofía; idea defendida a raíz que es "el amor, el amor que lleva su nombre, quien dispone y conduce la vida hacia la verdad" (Zambrano, 2001b, p. 15); postulado afirmado en que:

el amor nació, como el conocimiento filosófico, en Grecia, en un momento en que los Dioses, sin dejar de actuar, permiten al hombre buscar su ser. Pues diríase que siendo el amor el 'eros' griego avidez y hambre, era también creador de distancias, de límites, de frontera entre lo humano y lo divino (Zambrano, 1998, p. 27).

Con la identificación del amor, Zambrano declara la paradójica condición que distingue lo divino en relación al sujeto creyente, esto es: cercanía y distancia, y de paso, enseña las ideas centrales de su pensamiento, cuyo eje es el hombre y Dios, en donde el hombre pregunta y Dios se abre a la respuesta, pero a condición de que el que interroga se disponga a aceptar los contenidos que toda pregunta metafísica trae consigo. Esta dialéctica intersubjetiva es posible merced a que la composición del diálogo hombre-Dios refiere a situaciones dinámicamente entrelazadas en un eje identificado en 
el hombre mismo, puesto que no escapa a Zambrano que éste, el hombre, es lugar único de pregunta y respuesta. Percepción la suya que se traduce en la configuración misma de lo que se entiende en definitiva por hombre, es decir, como aquel que trae consigo la condición inefable del vínculo con lo sacro, y si no, la busca por necesidad constitutiva. (Este aspecto de la necesidad es una de las conclusiones a las cuales llega Cobos Navidad, pues su hipótesis es que Zambrano se preocupa de indicar de modo claro que: "la necesidad de lo divino, en la realización del hombre, el estudio del problema de Dios como realidad en el hombre y desde el hombre" (Cobos Navidad, 1998, p. 165).

\subsection{La trascendencia}

María Zambrano aborda el fenómeno religioso desde una episteme montada en la trascendencia como experiencia. Es aquí en donde anida la posibilidad de lograr la superación de los márgenes que caracterizan la existencia propiamente tal. Superación lograda merced a la condición de la apertura que, a su vez, define en sentido estricto la trascendencia como experiencia vital. En sí, la idea de la apertura se corresponde con la tesis siguiente:

(...) el que sueña pide salir de ese estado en que, desgraciado o feliz, yace como larva en su capullo. De ese estado de inmanencia, que no parecer ser propio de la vida humana. Pues si la idea inmanentista acerca del hombre correspondiese a la realidad, la vida sería como los sueños; la realidad, la circundante y la propia, sería solamente padecida, comentada como lo es en sueños, anotada, deformada, entrevista. Y aún las acciones con ella y aun sobre ella tendrían la misma condición: serían igualmente padecimiento, pasividad (Zambrano, 2004a, p. 16).

En suma, trascendencia valorizada por paradoja. Trascendencia como forma de darse la capacidad de salir del en-sí por parte del hombre (Cfr. Balsa, 2000). Situación que conforma la vía para comprender-hermenéuticamente la experiencia religiosa y, especialmente, cuando se persigue saber la implicancia antropológica que deviene del vínculo Dios-hombre. No es menor que en la respuesta a la pregunta encontremos claridad sobre el modo cómo aquel vínculo afecta al sujeto humano. Quizá la respuesta se explica mejor desde la fórmula afirmativa siguiente. Se trata de una afirmación que apunta directamente al espectro teleológico de la interrogante que pretende dilucidar el significado de Dios; empero, esta forma de ver la pregunta no proviene precisamente de la obra de Zambrano, sin embargo

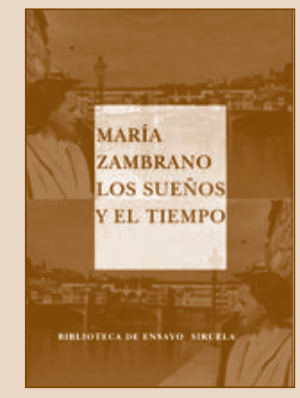

$$
\text { pregunta no proviene precisamente de la obra de Zambrano, sin embargo }
$$


es posible decir que no tendría reparo en compartirla: "Dios es una perenne pregunta porque es una perenne presencia" (González de Cardedal, 2004, p. 68). Aceptada la afirmación de sentido de la pregunta cómo una cuestión inseparable de la existencia humana, se entiende mejor el hecho que en la trascendencia como experiencia de apertura se halle la posibilidad de adquirir una adecuada comprensión de la religiosidad unida a la existencia concreta del sujeto, y que termina por ser un asunto epistémico efectivamente cierto como instancia de sentido para la realidad humana.

Siguiendo la línea interpretativa de la apertura, Zambrano nos pone de cara al reconocimiento del valor de verdad que la experiencia religiosa otorga a la existencia humana; desde ese lugar hermenéutico aparece un dato axiológico esencial como es tener que validar el diálogo entre Dios y el hombre, que culmina en un acto que vuelve al hombre persona en el entendido siguiente: más allá de ser hombre; algo plausible bajo el entendido que el sujeto se reconozca en la intimidad de su conciencia como creyente, disponible así a aceptar como clave de su existencia una realidad que lo sobrepasa. La hipótesis descansa en la experiencia de disponibilidad (propio del sentido de la trascendencia), a razón que en la disposición a lo otro se conjuga la idea de trascendencia propuesta como superación de los propios límites. A esta forma de entender la trascendencia como el modo constitutivo de ser persona, se suma la variable de la dependencia; variable que resume el sentido principal de la trascendencia, puesto que ahí radica el inicio del proceso de humanización.

Esta variable, a su vez, integra para su interpretación circunstancias culturales, y con lo cual el análisis-interpretativo de Zambrano encuentra la posibilidad de un desarrollo exponencial a raíz que asume características temporales, ya que en el caso del hombre moderno (o el actual por ser heredero de aquel), la hermenéutica destinada a comprender la relación, termina por ser una arquitectura cuyo eje es una cultura imbuida de construcciones racionales; construcciones que intervienen a la manera de límites puestos al tiempo, en particular me refiero a aquel tiempo de tener que asumir la disponibilidad a lo trascendente y, por tanto, respecto de la apertura que resulta ser aquel factor activo en el proceso de lograr tener una comprensión de lo divino.

Pero la advertencia de Zambrano sobre los límites de la razón, que la propia apertura devela, se ubica dentro de su crítica-descriptiva a la razón moderna. Escribe al respecto:

La filosofía moderna, origen de la física matemática, se queda en soledad para dar una imagen del cosmos, y al desprenderse por completo de 
la revelación queda librada a sí misma, como quería. Y el hombre que a la filosofía o a la ciencia se acoge, aun el hombre común que respira este clima, queda librado a su soledad humana, a la soledad del género humano sin cosmos y sin revelación. Y aquellos que vivían dentro aún de una religión determinada quedan escindidos, separados del pensamiento filosófico-científico y del ambiente intelectual y moral que de ellos emana, creyendo a medias y por partida doble (Zambrano, 1991, p. 12).

Visto el asunto de la limitación de la razón discursiva en la conquista de una inteligencia de lo religioso, por tanto de aquello que Zambrano reconoce habitando en la persona como acto esencial, nos topamos con que la explicación-crítica de Zambrano a la modernidad -en este caso se trata de la razón secular- asume la paradoja de rescatar una experiencia tipo que, llevada por la persona, se ve comprometida en un juego de cambios de perspectivas interpretativas onto-teológicas respecto de su propia situación como persona. Para dilucidar el sentido de este proceso interpretativo hay que buscar derechamente en la persona; al hacerlo, se debe cuidar mantener el criterio respecto que lo divino se caracteriza por ser "lo irreductible a lo humano" (Zambrano, 1993, p. 136). No obstante, es preciso aceptar que aquello caracterizado como independiente de la realidad humana sufre el percance del cambio, pues depende en su configuración de las formas que la propia experiencia religiosa le otorga para su conocimiento y comunicación al extremo que:

En la historia conocida siempre ha llegado un momento en que los dioses han muerto. Y es extraño. Lo divino, aquello que el hombre ha sentido como irreductible a su vida, sufre eclipses (...) Y en cualquiera de los casos ha llegado el instante terrible de que 'eso divino' irreductible a lo humano ha corrido la suerte de lo humano: pasar, ser vencido y aún morir (Zambrano, 1993, p. 136).

\section{EL SENTIDO DE LA INTERSUBJETIVIDAD}

Por otro lado, la variable de lo irreductible a lo humano, que Zambrano identifica como característica de lo divino, permanece como su característica más allá de los eclipses que las figuraciones que lo divino tiene o sufre en la historia. Esta situación da la posibilidad de interpretar la intersubjetividad atada al existir, para concluir en la idea de la dependencia como clave del existir mismo. Esto permite dar con la explicación -usando aquí la analogía de los bienaventurados que Zambrano estudia- de una existencia




construida en un "(...) orden divino que abraza sin tocarlas todas las cosas y todos los seres, todas las almas también, como una posesión amorosa que ni necesita ser sospechada en quien la recibe" (Zambrano, 1991, p. 69). Vale decir, de una situación que refiere a una inteligencia sobre lo religioso; siendo ésta una inteligencia que informa sobre el existir humano dependiendo y dependiente de lo divino, pero bajo el entendido que se existe-en-un elegir en lo divino como plena manifestación del depender del existir en-un-ser.

Ahora, llevando lo anterior a reconocer la validez de la fórmula en el proceso de lograr claridad del dato de fe, se perfila el valor de la contingencia humana como variable intersubjetiva. La explicación de su presencia está en que en la contingencia se resuelve la comprensión de aquello considerado necesario para la posibilidad del ser contingente mismo, en este caso: el hombre en cuando persona.

Admitida la fórmula de la participación de la contingencia en la realidad humana, se instala la idea de una intersubjetividad surgida como resultado de un diálogo entre dos polos, y en cuya revelación interviene la dependencia tanto como la contingencia unidas en un fondo sagrado -o fondo último de la realidad-; este fondo es comprendido a la manera de "suma realidad de la cual emana el carácter de todo lo que es real" (Zambrano, 1993, p. 32), ya que: “(...) el carácter sagrado de las cosas de la naturaleza es su realidad misma, no desvelada por la mente humana. Los caracteres de lo sagrado son los caracteres de la realidad tal como la sentimos espontáneamente" (Zambrano, 1989, p. 103).

Junto con lo anterior, véase la siguiente descripción del templo en ruinas. El relato declara un dato efectivo sobre algo que reúne en sí el carácter propio de lo sagrado: "Un templo en ruinas es el templo perfecto y al par la ruina perfecta. Y aún más: toda ruina tiene algo de templo; es por lo pronto un lugar sagrado. Lugar sagrado porque encarna la ligazón inexorable de la vida con la muerte" (Zambrano, 1993, p. 254). A renglón seguido, da una explicación del vínculo vida-muerte manteniendo para estos efectos la metáfora indicada de la ruina:

De toda ruina emana algo divino que brota de la misma entraña de la vida humana; algo que nace del propio vivir humano cuando se despliega en toda su plenitud sin que haya venido a posarse como regalo concedido de lo alto; algo ganado por haber apurado la esperanza en su extremo límite y soportado su fracaso y aún su muerte: el algo que queda del todo que pasa (Zambrano 1993, p. 254).

¿Qué concluir de todo esto? En Zambrano la contingencia refiere en su 
significación a un tipo de existencia sostenida en la fragilidad de un diálogo, es decir, de una existencia que depende de la aceptación por parte del sujeto de lo otro, puesto que ve en el otro su posibilidad de existencia; de lo contrario queda absorbido precisamente por la contingencia o inmanencia, desapareciendo con esta cuestión su propia posibilidad de existencia. Se trata, por tanto, de un intento por explicar que todo consiste en un diálogo que actúa como criterio hermenéutico con sentido poiético, vale decir, creador de existencia. Esta característica de creador del diálogo intersubjetivo determina que la primera aproximación a la sacralidad produce una imagen que guarda en sí la perspectiva de la pertinencia sobre la verdad misma de la relación dialógica. Al respecto véase lo que dice Zambrano: "esta primera forma de trato con la realidad tenía que darse en una imagen" (Zambrano, 1993, p. 30). Interpretación que remite hermenéuticamente a la fragilidad de todo ente que no depende de sí, sino de un Ser que lo sostiene.

Se entiende que el diálogo intersubjetivo declara la presencia de una relación dinámica construida desde la dependencia como nota distintiva de todo ente. De esta forma, lo singular de la hermenéutica a la religiosidad que realiza Zambrano concluye en la idea que la dependencia reúne las notas de la contingencia como condición última de la comprensión del ser sacro (Cfr. Ortega Muñoz, 1994; especialmente el Cap. II). En fin, lo que prima en el diálogo intersubjetivo es, y de modo principal, el rol de la figura humana que se distingue por la contingencia. Paradójico asunto, ya que al final termina siendo la contingencia el factor interpretativo desde el cual se elabora el proceso que conduce a la inteligencia de cómo es que Dios habita en él. Inteligencia sobre Dios que implica al mismo tiempo inteligencia de Dios. El alcance de tal experiencia es mayúsculo, pues se concluye que por la conciencia de la finitud como marca de su existencia -conciencia nacida además desde la estructura dependiente y contingente de la relación-, el hombre se hace de una idea suya como persona, vale decir, como un alguien que es, precisamente, aquel alguien por un encuentro realizado en una ubicación social e histórica determinada con un otro. De ahí que la figura del otro sea constitutiva de su ser existencial. Esto se puede interpretar en el contexto hermenéutico a la descripción del templo en ruinas, puesto que ahí Zambrano ofrece una explicación metafórica sobre el significado filosófico de la existencia: "las ruinas vienen a ser la imagen acabada del sueño que anida en lo más hondo de la vida" (Zambrano, 1993, p. 255). De suyo, el texto soporta una interpretación que acepta la referencia a un algo construido por dos realidades, las que actuando en un fondo común de esencias descubren al sujeto los significantes esenciales que hablan de la 
vida y la muerte. Pero con la salvedad que el fenómeno revelativo sucede a la manera de un continuo esencial a la relación, vale decir, como un ocurrir en la intersubjetividad misma en donde la persona esculpe, desde su razón (poiética), el sentido de la relación, por tanto, el lugar de la divinidad y sus efectos en él. Pero además la interpretación avisa sobre la potencial ruptura de la comprensión racional de sentido del diálogo; ruptura que se relaciona con la caducidad del sujeto comprensivo a causa de su carácter contingente, hecho que remite al peligro de no lograr tener el significado de Dios, lo que afectaría la idea de persona. Este riesgo se ve creciente por el factor moderno de la secularización.

Para Zambrano, el ambiente secularizado tiende a hacer de la razón un instrumento de negación del diálogo Dios-persona; lo cual, ciertamente, conduce a la disolución de la capacidad del hombre para descubrir aquello que es propio de la divinidad y que, en el fondo, corresponde a lo sagrado que se visualiza ahí en las formas de lo divino. Aceptando el riesgo que trae consigo la secularización, se atreve a preguntar si el hombre "puede en verdad, estar entera, absolutamente, solo" (Zambrano, 1993, p. 182), vale decir: ¿sin Dios? Negando tal posibilidad, nos enseña que la viabilidad de comprender la experiencia religiosa pide del sujeto un acto epistémico en donde la experiencia de apertura es la condición, pero en el entendido de que es condición para la hermenéutica que pretende resolver el dilema de la existencia y, por tanto, condición además que permite asumir la existencia de una realidad con características de substrato para el hombre. Así la apertura, entendida aquí como mecanismo epistémico, acerca al hombre a la verdad, es decir: a aquello que se presenta como substrato suyo, pero que precisa por parte del sujeto de reconocimiento y aceptación como tal verdad.

En suma, la apertura entendida como proceso facilita al sujeto la identificación de puntos o notas propias de la sacralidad. Ahora bien, para que ocurra el suceso revelativo de las notas de lo sacro - notas que son el soporte de la relación entre Dios y el hombre-, debe haber una verdad que, al guardar en su seno la condición de abrirse a otro para su apropiación, convoque a este otro para su contemplación y conocimiento.

\section{CONCLUSIÓN}

La propuesta onto-teológica de Zambrano habla de una experiencia dialógica entre Dios y persona, en cuyo eje dialéctico se hallan juntas la li- 
bertad y la verdad. Ambas conforman la trama del contexto intersubjetivo que caracteriza la apertura como experiencia existencial. Esta situación se hace evidente, por ejemplo, en el caso de aceptar que es "la libertad que lo hace despertar" (Zambrano, 1971, p. 28) a la vida. Pero a una vida que se establece desde la relación con una realidad de orden trascendente. Ahora bien, si lo indicado efectivamente describe la religiosidad como experiencia constitucional, entonces lo que enseña sobre el valor de la religiosidad es mayor. Ontológicamente mayor, pues por esta experiencia se termina por convertir al hombre en persona y, por tanto, en sujeto cultural. Tal óptica interpretativa descansa en la fórmula hermenéutica que dice que persona y cultura son dos realidades sincrónicas activas en un solo sujeto, pues es gracias a esta sincronía que es plausible la conquista y desarrollo de una identidad que hace a la persona ser único; único a raíz que es original la experiencia de aquello que lo trasciende, y que al mismo tiempo lo define como tal sujeto. En efecto, para Zambrano:

(...) la persona incluye el yo y lo trasciende, pues el yo es vigilia, atención; inmóvil, es una especie de guardián. La persona, como su mismo nombre lo indica, es una forma, una máscara con la cual afrontamos la vida, la relación y el trato con los demás, con las cosas divinas y humanas. Esa persona es moral, verdaderamente humana, cuando porta dentro de sí la conciencia, el pensamiento, un cierto conocimiento de sí mismo y un cierto orden, cuando se sitúa previamente a todo trato y a toda acción en un orden; cuando recoge lo más íntimo del sentir, la esperanza (Zambrano, 2004b, p. 65).

En suma, libertad y verdad son, en buenas cuentas, las condiciones de origen de la experiencia religiosa. Sin estas condiciones ocurriría lo que Zambrano avisa: "Cerrada a la libertad, el hombre sujeto a ser libre, encuentra que todas las cosas son nada. Mas, la primera originaria 'apertura' de la vida humana a las cosas que la rodean, a las circunstancias, es padecerlas" (Zambrano, 1993, p. 188); lo que le permite concluir aquello de que:

las cosas que no son nada son algo cuando se les padece. Y el propio ser, el sujeto -anulado en el sentir de la nada- se yergue cuando es fiel a su doble condición de haber de sufrir al propio tiempo la cárcel de las circunstancias y su propia libertad: "Somos necesariamente libres" (Zambrano, 1993, p. 188).

En suma, con la determinación de la arquitectura de la religiosidad, y 
desde su aceptación como hecho de existencia real, es plausible sostener que los elementos relativos a la vigencia de la cuestión religiosa intervienen conectando un punto axial para su inteligencia; este punto es el estatus de la palabra:

la palabra verdadera sin opacidad y sin sombra, dada y recibida en el mismo instante, consumida sin desgaste; centella que se reencendía cada vez. Palabra, palabras no destinadas, como las palomas de después, al sacrificio de la comunicación, atravesando vacíos y dinteles, fronteras, palabras sin peso de comunicación alguna ni notificación. Palabras de comunión (Zambrano, 2011a, p. 82).

\section{REFERENCIAS}

Balza, I. (2000). Tiempo y escritura en María Zambrano. Bilbao: Iralka, Donostia.

Bungard, A. (2000). Más allá de la filosofía. Sobre el pensamiento filosófico-místico de María Zambrano. Madrid: Trotta. . (2005). "La placenta de la sombra de la poesía". En Mora García, J. L.; Moreno Yuste, J. M. (Eds.). Pensamiento y palabra: En recuerdo de María Zambrano (1904-1991) (pp. 123-136). Madrid : Junta de Castilla y León.

Cobos Navidad, M. (1998). "Recuperar lo divino en el hombre”. En Murillo, I. (Ed.), Dios, hombre, praxis. Filosofía cristiana y cristianismo (pp. 163-172). Madrid: Diálogo Filosófico.

González de Cardedal, O. (2004). Dios. Salamanca: Sígueme.

Izquierdo, A. (2003). La filosofía contra la religión. Madrid: Edaf.

Marcel, G. (1967). “El concepto de herencia espiritual”. En Ruitenbeek, H. M. (Ed.). El dilema de la sociedad: organización (pp. 61-74). Buenos Aires: Paidós.

Martín Velasco, J. (1995). El encuentro con Dios. Madrid: Ed. Caparrós.

Ortega Muñoz, J. A. (1994). Introducción al pensamiento de María Zambrano. México: FCE.

Ricoeur, P. (2008). Fe y filosofía. Problemas del lenguaje religioso. Buenos Aires: Ed. Pontificia U. Católica Argentina (UCA) - Prometo Libros.

Schaeffler, R. (2003). Filosofía de la religión. Salamanca: Sígueme.

Zambrano, M. (1971). El sueño creador. En Obras reunidas. Madrid: Aguilar. . (1986). Los intelectuales y el drama de España. Barcelona: Anthropos. . (1989). Notas de un método. Madrid: Mondadori. . (1991). Los bienaventurados. Madrid: Siruela. . (1993). El hombre y lo divino. México: FCE. . (1998). Dos fragmentos sobre el amor. Madrid: Club Internacional del Libro. 
. (2001a). Filosofía y poesía. México: FCE.

(2001b). La confesión: género literario. Madrid: Siruela.

. (2004a). Los sueños y el tiempo. Madrid: Siruela.

. (2004b). Persona y democracia. Madrid: Siruela.

. (2011a). Claros del bosque. Madrid: Catedra.

. (2011b). El pensamiento vivo de Séneca. Madrid: Cátedra. 